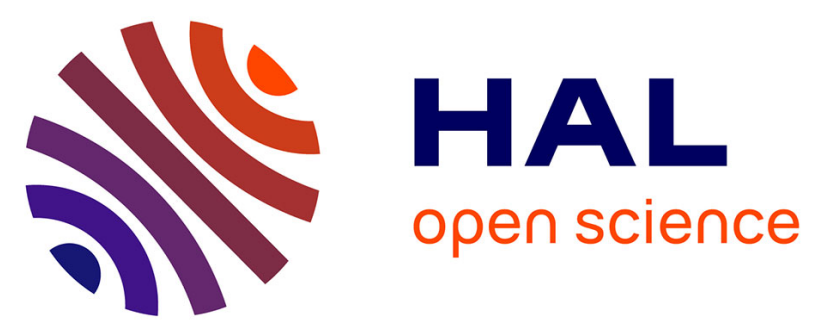

\title{
Evaluation of operational radiances for the Measurements of Pollution in the Troposphere (MOPITT) instrument $\mathrm{CO}$ thermal band channels
}

M.-N. Deeter, L.-K. Emmons, G.-L. Francis, D.-P. Edwards, J.-C. Gille, J. Warner, B. Khattatov, D.-C. Ziskin, J.-C. Lamarque, S.-P. Ho, et al.

\section{To cite this version:}

M.-N. Deeter, L.-K. Emmons, G.-L. Francis, D.-P. Edwards, J.-C. Gille, et al.. Evaluation of operational radiances for the Measurements of Pollution in the Troposphere (MOPITT) instrument CO thermal band channels. Journal of Geophysical Research: Atmospheres, 2004, 109 (D3), pp.D03308. 10.1029/2003JD003970 . hal-00136329

\section{HAL Id: hal-00136329 \\ https://hal.science/hal-00136329}

Submitted on 1 Feb 2022

HAL is a multi-disciplinary open access archive for the deposit and dissemination of scientific research documents, whether they are published or not. The documents may come from teaching and research institutions in France or abroad, or from public or private research centers.
L'archive ouverte pluridisciplinaire HAL, est destinée au dépôt et à la diffusion de documents scientifiques de niveau recherche, publiés ou non, émanant des établissements d'enseignement et de recherche français ou étrangers, des laboratoires publics ou privés. 


\title{
Evaluation of operational radiances for the Measurements of Pollution in the Troposphere (MOPITT) instrument $\mathrm{CO}$ thermal band channels
}

\author{
M. N. Deeter, ${ }^{1}$ L. K. Emmons, ${ }^{1}$ G. L. Francis, ${ }^{1}$ D. P. Edwards, ${ }^{1}$ J. C. Gille, ${ }^{1}$ J. X. Warner, ${ }^{1}$ \\ B. Khattatov, ${ }^{1}$ D. Ziskin, ${ }^{1}$ J.-F. Lamarque, ${ }^{1}$ S.-P. Ho, ${ }^{1}$ V. Yudin, ${ }^{1}$ J.-L. Attie, ${ }^{2}$ D. Packman, ${ }^{1}$ \\ J. Chen, ${ }^{1}$ D. Mao, ${ }^{1}$ James R. Drummond, ${ }^{3}$ Paul Novelli, ${ }^{4}$ and Glen Sachse ${ }^{5}$ \\ Received 10 July 2003; revised 3 November 2003; accepted 17 November 2003; published 14 February 2004.
}

[1] The ability of operational radiative transfer models to accurately predict remote sensing instrument observations (e.g., calibrated radiances) over a wide variety of geophysical situations is critical to the performance of trace gas retrieval algorithms. As part of the validation of the Measurements of Pollution in the Troposphere (MOPITT) satellite instrument, we present a technique for comparing operational calibrated thermal band $(4.7 \mu \mathrm{m})$ Earth-view MOPITT radiances with corresponding values calculated using the MOPITT operational radiative transfer model. In situ carbon monoxide (CO) profiles sampled from aircraft in coordination with MOPITT overpasses serve as the foundation for MOPITT validation. Characteristics of radiance errors due to in situ sampling characteristics, $\mathrm{CO}$ temporal and spatial variability, and surface emissivity are discussed. Results indicate that radiance biases for most of the MOPITT thermal channel radiances are typically on the order of $1 \%$. Observed radiance biases are largest and most variable for the pressure modulation cell difference-signal radiances, probably because of the lack of in situ data in the upper troposphere and lower stratosphere. INDEX TERMS: 0345 Atmospheric Composition and Structure: Pollution - urban and regional (0305); 0365 Atmospheric Composition and Structure: Troposphere-composition and chemistry; 0394 Atmospheric Composition and Structure: Instruments and techniques; 1640 Global Change: Remote sensing; KEYWORDS: MOPITT, validation, radiative transfer model

Citation: Deeter, M. N., et al. (2004), Evaluation of operational radiances for the Measurements of Pollution in the Troposphere (MOPITT) instrument CO thermal band channels, J. Geophys. Res., 109, D03308, doi:10.1029/2003JD003970.

\section{Introduction}

[2] The Measurements of Pollution in the Troposphere (MOPITT) remote sensing instrument was launched on 18 December 1999 aboard the EOS Terra satellite. MOPITT was designed to exploit principles of gas correlation radiometry to independently measure tropospheric carbon monoxide $(\mathrm{CO})$ and methane $\left(\mathrm{CH}_{4}\right)$. Two classes of products from MOPITT are publicly available. The Level 1 product consists of the 16 geolocated and calibrated radiances (along with corresponding uncertainty values). Of these radiances, 12 are sensitive to $\mathrm{CO}$, and four to $\mathrm{CH}_{4}$. The Level 2 product consists of the retrieved trace gas quantities corresponding to each geolocated MOPITT

\footnotetext{
${ }^{1}$ Atmospheric Chemistry Division, National Center for Atmospheric Research, Boulder, Colorado, USA.

${ }^{2}$ Laboratoire d'Aérologie, Observatoire Midi Pyrénées, Toulouse, France.

${ }^{3}$ Department of Physics, University of Toronto, Toronto, Ontario, Canada.

${ }^{4}$ Climate Monitoring and Diagnostics Laboratory, National Atmospheric and Oceanic Administration, Boulder, Colorado, USA.

${ }^{5}$ NASA Langley Research Center, Hampton, Virginia, USA.

Copyright 2004 by the American Geophysical Union. 0148-0227/04/2003JD003970
}

pixel (in addition to several retrieval by-products, including surface temperature). As shown below, radiance errors can directly lead to significant retrieval errors. Therefore biases in the radiances should be thoroughly quantified before attempting to interpret retrieval validation results. The MOPITT retrieval algorithm is based on the maximum likelihood technique, and relies heavily on a fast operational radiative transfer model known as MOPFAS. The degree to which this model is able to accurately predict the observed MOPITT radiances over highly variable atmospheric and surface conditions is a main determinant of the accuracy of the MOPITT Level 2 product. In the following, we quantify the agreement between the MOPITT thermal channel radiances and corresponding model-calculated values. Validation of the MOPITT CO retrieval product is described in a companion paper [Emmons et al., 2004].

[3] The remainder of this paper is organized as follows. Following a description of the fundamental operating principles underlying the MOPITT instrument and a brief review of MOPITT's operational history, the need to quantify MOPITT radiance biases is motivated with a demonstration of the simulated effects of radiance biases on retrieval errors. Then, details of the aircraft in situ sampling 
Table 1. MOPITT CO Thermal Channel Modulator Characteristics

\begin{tabular}{ccc}
\hline Channel & Modulator Type & Cell Pressure, mbar \\
\hline 1 & length & 200 \\
3 & pressure & $50-100$ \\
5 & length & 800 \\
7 & pressure & $25-50$ \\
\hline
\end{tabular}

program which is the basis of MOPITT validation are provided. We then describe the methodology employed to calculate the validation radiances. Results are reported in terms of statistical comparisons between the Level 1 (observed) and validation (model-calculated) radiances for each of the MOPITT thermal channel radiances at each of the validation sites. Finally, several potential geophysical sources of radiance bias are considered.

\section{Principles of MOPITT Operations}

\subsection{Instrument Description}

[4] Modulation cells in the MOPITT instrument containing each of the "target" trace gases (carbon monoxide and methane) act as high-spectral-resolution optical filters. The filtering characteristics of the cells vary dynamically either through modulation of the cell pressure or modulation of the optical path length [Taylor, 1983; Tolton and Drummond, 1997]. When combined with a phase-sensitive detection system, the modulation produces two signals with quite different spectral responses. Specifically, gas correlation radiometry produces two signals which measure radiation (1) in the spectral windows between the absorption lines of the gas contained in the cell and (2) in spectral regions immediately adjacent to the absorption lines of the gas contained in the cell [Edwards et al., 1999]. Signals primarily sensitive to the spectral window regions between the target gas absorption lines are derived from an average measurement of the modulated signals and are referred to as "A" signals. These signals are characterized by relatively low atmospheric absorption (high mean transmittance). Signals corresponding to spectral regions close to the target gas absorption lines are derived from a difference measurement of the modulated signals and are referred to as " $D$ " signals. These signals are relatively much more sensitive to atmospheric target gas concentrations than the A signals. Throughout the remainder of this paper, the term "signal" generally refers to raw instrument output (typically measured in digital counts), whereas "radiance" refers to signals which have been calibrated and geolocated, i.e., the Level 1 product.

[5] For retrievals of $\mathrm{CO}$, MOPITT produces " $\mathrm{A}$ " and "D" signals in two distinct spectral bands. The MOPITT "thermal band" signals exploit a set of $\mathrm{CO}$ absorption lines near $4.6 \mu \mathrm{m}$ and are the subject of this study. The MOPITT "solar band" signals exploit a set of $\mathrm{CO}$ absorption lines near $2.3 \mu \mathrm{m}$. These signals are not currently exploited in operational CO retrievals [Deeter et al., 2003]. (Radiance bias analyses for the MOPITT solar band channels will be reported in future publications.) Four CO modulation cells (including two pressure-modulated cells and two lengthmodulated cells) generate four thermal band A signals and four thermal band D signals. Corresponding A and D signals derived from the same optical path (and therefore the same modulation cell) together constitute one channel of the instrument. Characteristics of the four MOPITT thermal band $\mathrm{CO}$ channels and corresponding modulation cells are listed in Table 1. By virtue of the unique filtering characteristics of each of the four cells, the four thermal band D signals are each sensitive to $\mathrm{CO}$ in effectively different (but overlapping) layers of the troposphere. This distinguishing feature is the basis of MOPITT's ability to resolve the CO vertical profile. (The horizontal resolution of MOPITT observations is defined by the field of view which measures approximately 22 by $22 \mathrm{~km}$ at nadir.) Typical D-signal "weighting functions" (defined as the derivative of the radiance with respect to the $\mathrm{CO}$ profile), are shown in Figure 1. As revealed in the figure, all of the signals exhibit relatively weak sensitivity near the surface. The 5D signal peaks closest to the surface, whereas the $7 \mathrm{D}$ signal exhibits the highest-altitude peak.

\subsection{Retrieval Algorithm Description}

[6] Following a cloud-detection stage [Warner et al., 2001], an optimal estimation-based retrieval algorithm [Pan et al., 1998; Deeter et al., 2003] and a fast radiative transfer model (see next paragraph) are used to invert the calibrated A and D satellite radiances to determine the tropospheric trace gas concentrations. Retrievals of methane are based on four measured A and D radiances in a band around $2.2 \mu \mathrm{m}$, and rely on solar radiation reflected from the Earth's surface. Retrievals of $\mathrm{CO}$ involve up to eight thermal band radiances and four solar band radiances. Calibrated measurements of the $\mathrm{CO}$ thermal band radiances, which are the subject of this study, allow retrievals of $\mathrm{CO}$ for both daytime and nighttime satellite overpasses (unlike methane). They are also the key to MOPITT's ability to retrieve information regarding the $\mathrm{CO}$ vertical profile.

[7] Both the cloud detection stage and retrieval algorithm exploit a fast radiative transfer model known as MOPFAS [Edwards et al., 1999]. MOPFAS relies on radiative parameterizations as a means of avoiding time-consuming spectral integrations. A regression scheme based on the OPTRAN technique [McMillin et al., 1995] is applied to establish a

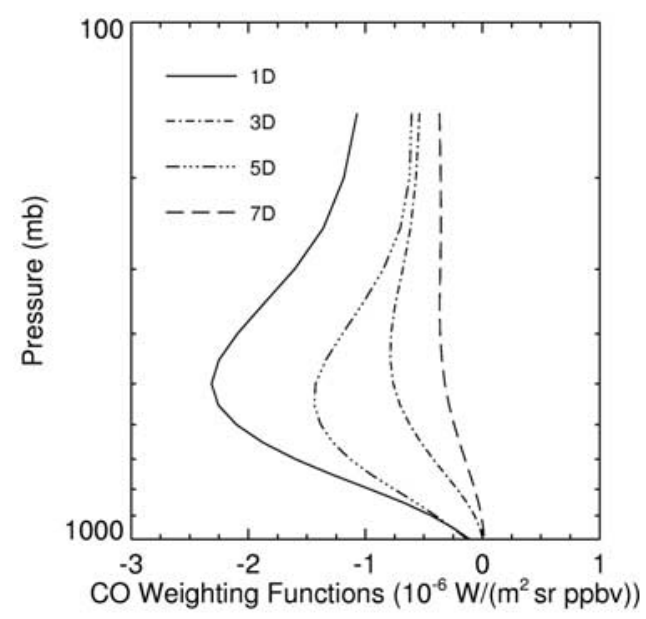

Figure 1. Typical weighting functions (i.e., derivatives of the radiance with respect to perturbations in the $\mathrm{CO}$ profile) for the MOPITT thermal band D signals. 


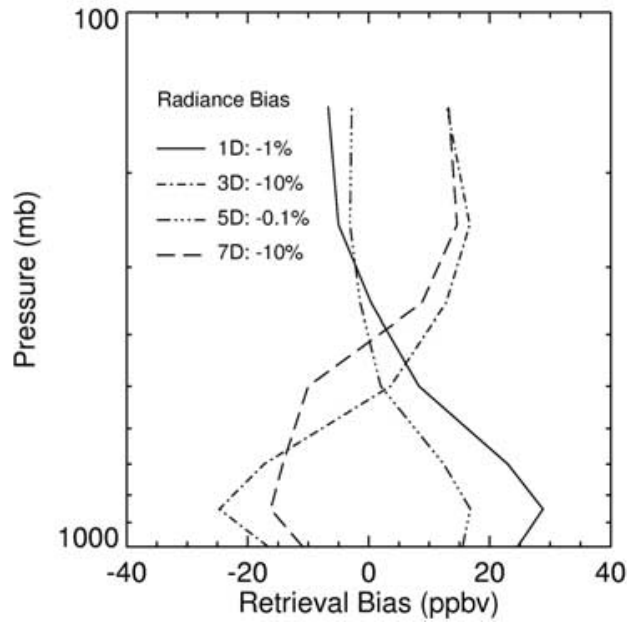

Figure 2. Simulated mean retrieval errors produced by (1) $-1.0 \%$ radiance bias in $1 \mathrm{D}$ radiance, $(2)-10 \%$ radiance bias in $3 \mathrm{D}$ radiance, (3) $-0.1 \%$ radiance bias in $5 \mathrm{D}$ radiance, and (4) $-10 \%$ radiance bias in $7 \mathrm{D}$ radiance.

correspondence between channel-integrated transmittances and atmospheric state profiles. The regression maps a set of predictors, obtained from the state profiles, onto corresponding values of channel transmittance obtained from a radiative transfer model (known as MOPABS) with line-by-line accuracy. The predictors include functions of the target gas $\left(\mathrm{CO}\right.$ or $\left.\mathrm{CH}_{4}\right)$ vertical profile, water vapor profile, and temperature profile. The regression coefficients are precomputed through a least-squares fit over a representative atmospheric ensemble. MOPFAS-computed radiances typically agree with line-by-line calculations to within $1 \%$, but are approximately 2 orders of magnitude faster to compute [Edwards et al., 1999].

\subsection{Chronology of MOPITT Operations}

[8] MOPITT's host, the EOS Terra satellite, was launched on 18 December 1999. MOPITT began standard operations on 2 March 2000. Normal operations continued until 7 May 2001, when one of MOPITT's two cooling systems failed. The cooler failure permanently disabled channels $1-4$ and interrupted MOPITT operations for a period of several months for diagnostics. MOPITT resumed operations in August 2001, with channels 5-8 all operational. However, during the period while MOPITT was off-line, instrument operations for channel 7 were reconfigured. Specifically, the stroke amplitude for the channel 7 pressure modulation cell (PMC) was increased in order to increase the signal to noise ratio for the 7D radiance. Software revisions were incorporated into both the radiance calibration algorithm and the forward radiative transfer model to account for the instrument reconfiguration. Because of the loss of channels 1-4 and the instrument reconfiguration, MOPITT products available for the period from March 2000 through May 2001 may be qualitatively different than the same products available for the period since August 2001. These two phases of MOPITT operations have been designated "Phase I" and "Phase II" respectively. The impact of the loss of channels $1-4$ on MOPITT retrieval results will be discussed in a future publication. MOPITT products for Phase I and Phase II are studied separately. Results for Phase II are based on MOPITT data acquired from August 2001 through July 2002.

\section{MOPITT Validation}

\subsection{Radiance Bias Effects}

[9] MOPITT calibrated radiances and $\mathrm{CO}$ retrievals are produced in sequential processing streams. A companion paper [Emmons et al., 2004] describes the validation of the MOPITT CO retrieval product. Here we describe the technique used to evaluate the calibrated thermal channel radiances and present results. Radiance evaluation and retrieval validation are complementary. Radiance evaluation is necessary to demonstrate quantitative agreement between the observed calibrated radiances and the operational forward model over widely varying atmospheric states and geographical settings. Interpretation of the retrieval validation results is simpler if characteristics (especially biases) of the radiances are already well understood.

[10] The effects of radiance biases on retrieval performance vary considerably according to which radiance is biased. Generally, however, retrieval biases vary inversely with the sensitivity of the radiances to varying CO. Thus, for a radiance exhibiting relatively strong sensitivity to varying $\mathrm{CO}$, the retrieval bias resulting from a given bias in that radiance will be relatively small. Mean retrieval errors obtained by simulating retrievals for a set of 157 in situ profiles (drawn from eight atmospheric chemistry field campaigns and two fixed monitoring stations) with biases separately applied to each of the thermal channel D radiances are shown in Figure 2. (Except for the results shown for $5 \mathrm{D}$, all retrieval simulations were performed using the current standard Phase I operational retrieval configuration, which is based only on the 7A, 1D, 3D, and 7D radiances [Deeter et al., 2003]. Simulation results for the 5D radiance were based on an experimental configuration which exploits

Table 2. MOPITT In Situ (Flask Sampling) Standard Validation Sites ${ }^{\mathrm{a}}$

\begin{tabular}{|c|c|c|c|c|c|c|c|}
\hline \multirow[b]{2}{*}{ Validation Site } & \multirow[b]{2}{*}{ Code } & \multirow[b]{2}{*}{ Latitude } & \multirow[b]{2}{*}{ Longitude } & \multicolumn{2}{|c|}{ Phase I } & \multicolumn{2}{|c|}{ Phase II } \\
\hline & & & & Flights & Overpasses & Flights & Overpasses \\
\hline Poker Flats, Alaska & PFA & $65.1^{\circ} \mathrm{N}$ & $147.5^{\circ} \mathrm{W}$ & 13 & 4 & 13 & 4 \\
\hline Harvard Forest, Massachusetts & HFM & $42.5^{\circ} \mathrm{N}$ & $71.2^{\circ} \mathrm{W}$ & 10 & 3 & 18 & 12 \\
\hline Carr, Colorado & CAR & $40.1^{\circ} \mathrm{N}$ & $104.1^{\circ} \mathrm{W}$ & 25 & 9 & 24 & 12 \\
\hline Molokai, Hawaii & HAA & $21.4^{\circ} \mathrm{N}$ & $157.2^{\circ} \mathrm{W}$ & 18 & 14 & 24 & 26 \\
\hline Rarotonga, Cook Islands & RTA & $21.2^{\circ} \mathrm{S}$ & $159.8^{\circ} \mathrm{W}$ & 9 & 4 & 21 & 19 \\
\hline
\end{tabular}

${ }^{\mathrm{a}}$ Total overpasses for each site only include MOPITT scenes for which at least 10 clear-sky MOPITT pixels were observed within 200 km and 14 hours of an in situ sampling flight. 
Table 3. MOPITT in Situ Validation Field Campaigns

\begin{tabular}{|c|c|c|c|c|c|}
\hline Field Campaign & Code & Geographical Area & Duration & Flights & Overpasses \\
\hline Citation charters & CIT & western United States & October 2000 & 6 & 5 \\
\hline TRACE-P & TRP & western Pacific Ocean & February-April 2001 & 7 & 3 \\
\hline SAFARI-2000 & $\mathrm{S} 2 \mathrm{~K}$ & southern Africa & August-September 2000 & 11 & 7 \\
\hline
\end{tabular}

the $5 \mathrm{D}$ radiance in addition to the standard set of radiances.) The simulations reveal that a radiance bias of only $-1 \%$ in the 1D radiance produces a retrieval bias at 850 mbar of approximately $30 \mathrm{ppbv}$. (The mean $\mathrm{CO}$ mixing ratio value near the surface over all of the simulation profiles is approximately 120 ppbv.) Even more dramatically, a bias of the $5 \mathrm{D}$ radiance of only $-0.1 \%$ produces a retrieval bias near the surface of more than $15 \mathrm{ppbv}$. (This result is due to the relatively low $\mathrm{CO}$ sensitivity of the $5 \mathrm{D}$ radiance.) Application of $10 \%$ biases to the $3 \mathrm{D}$ and $7 \mathrm{D}$ radiances produces retrieval biases of approximately -10 to $-20 \mathrm{ppbv}$ near the surface and 10 to $15 \mathrm{ppbv}$ in the upper troposphere. As demonstrated by the simulation results for the $1 \mathrm{D}$ and $5 \mathrm{D}$ radiances, small radiance errors may propagate in the retrieval algorithm to become relatively large retrieval errors. Thus it is essential to quantify the agreement between the observed calibrated radiances and values predicted by the forward model as precisely as possible. Quantifying the radiance biases in the MOPITT channels is also an important first step in identifying and correcting errors in the data used to develop the forward model. For example, analysis of the MOPITT thermal channel A radiances previously revealed a shift in the nominal spectral characteristics of the MOPITT optical filters which was subsequently corrected [Deeter et al., 2002].

[11] In brief, the goal of this study is to compare satellitemeasured radiances with model-calculated radiances in situations where all relevant inputs to the operational forward radiative transfer model (i.e., meteorological data, trace gas profiles, etc.) can be accurately specified. Demonstrated quantitative agreement between the measured and model-calculated radiances over widely varying atmospheric conditions is essential to verifying the applicability of the forward model used operationally in MOPITT retrievals. General disagreement between the observed and modelcalculated radiances would suggest a problem with either the instrument, the forward model, or ancillary geophysical data used in the retrievals (e.g., temperature and water vapor profiles), and would compromise the quality of the MOPITT retrievals.

\subsection{In Situ Data}

[12] In situ flask sampling and subsequent laboratory trace-gas analysis serve as the foundation for MOPITT validation efforts. NOAA's Climate and Monitoring Diagnostics Laboratory (CMDL) was engaged to support MOPITT validation by conducting regular in situ $\mathrm{CO}$ profile measurements at the five geographically dispersed sites defined in Table 2. Except for the flights at Carr, Colorado, sampling flights were coordinated with Terra overpasses. Individual flights required about $1.5 \mathrm{hr}$ to complete and were timed such that the overpass would occur at the midway point of the sampling flight. During Phase I, in situ profile data were also obtained through the involvement of CMDL in the field campaign "Southern African Regional Science Initiative" (SAFARI-2000, see http://www.safari2000.org) and through the involvement of NASA in "Transport and Chemical Evolution over the Pacific" (TRACE-P) [Jacob et al., 2003]. Details of the aircraft sampling flights conducted in coordination with MOPITT overpasses during these campaigns and during several special opportunity flights in the western United States (on the Citation aircraft) are listed in Table 3.

[13] For the CMDL flights, trace gas volume mixing ratios were determined by gas chromatography followed by $\mathrm{HgO}$ reduction detection [Novelli et al., 1998]. All measurements were referenced to the CMDL/WMO 2000 $\mathrm{CO}$ scale. For each vertical profile, flask samples were collected at levels from the surface and up to the maximum aircraft altitude (usually between 7 and $8 \mathrm{~km}$ ). Typical vertical sampling resolution was about $0.5 \mathrm{~km}$. Reported uncertainties in the laboratory-derived in situ volume mixing ratio values are approximately a few percent [Novelli et al., 1998]. Although not directly relevant to this study, the same flask samples used to quantify $\mathrm{CO}$ mixing ratio were also analyzed for $\mathrm{CO}_{2}$ and $\mathrm{CH}_{4}$. In situ profiles used for validation are shown in Figure 3. The solid section of each plotted profile represents that portion of the profile obtained by interpolating in situ data. As described below, output from a chemical transport model was used to supplement the in situ data at higher levels.

[14] Separate from the CMDL measurements, TRACE-P in situ profiles (also shown in Figure 3) were collected from two aircraft over the North Pacific during the period February-April 2001 [Jacob et al., 2003]. On seven flights the DC-8 aircraft collected data in vertical profiles $(0-$ $12 \mathrm{~km}$ ) coincident with MOPITT overpasses, with four of these cases in clear-sky conditions suitable for validation comparisons. In situ $\mathrm{CO}$ measurements for these profiles were made by the fast-response tunable diode laser instrument Differential Absorption CO Measurement (DACOM) [Sachse et al., 1987]. The time response of the measurements is $1 \mathrm{~s}$ with a precision of approximately $1 \%$. Measurement accuracy using the DACOM technique is closely tied to the accuracy of reference gases obtained from CMDL.

[15] The MOPITT weighting functions shown in Figure 1 describe the sensitivity of each of the D-signal radiances to changes in the $\mathrm{CO}$ profile. Mathematically, the weighting functions are calculated as the derivative of the radiance (as calculated with the operational forward radiative transfer model) with respect to the discretized volume mixing ratio profile. Typically, the weighting functions for the thermal channel D radiances tend toward zero at altitudes above the 100 mbar level [Pan et al., 1998]. Thus, for validation, aircraft in situ profiles would ideally span the entire troposphere and lower stratosphere. However, the CMDL aircraft from which the in situ profiles are recorded typically can not reach altitudes higher than $8 \mathrm{~km}(\sim 350 \mathrm{mbar})$. Thus, for the 

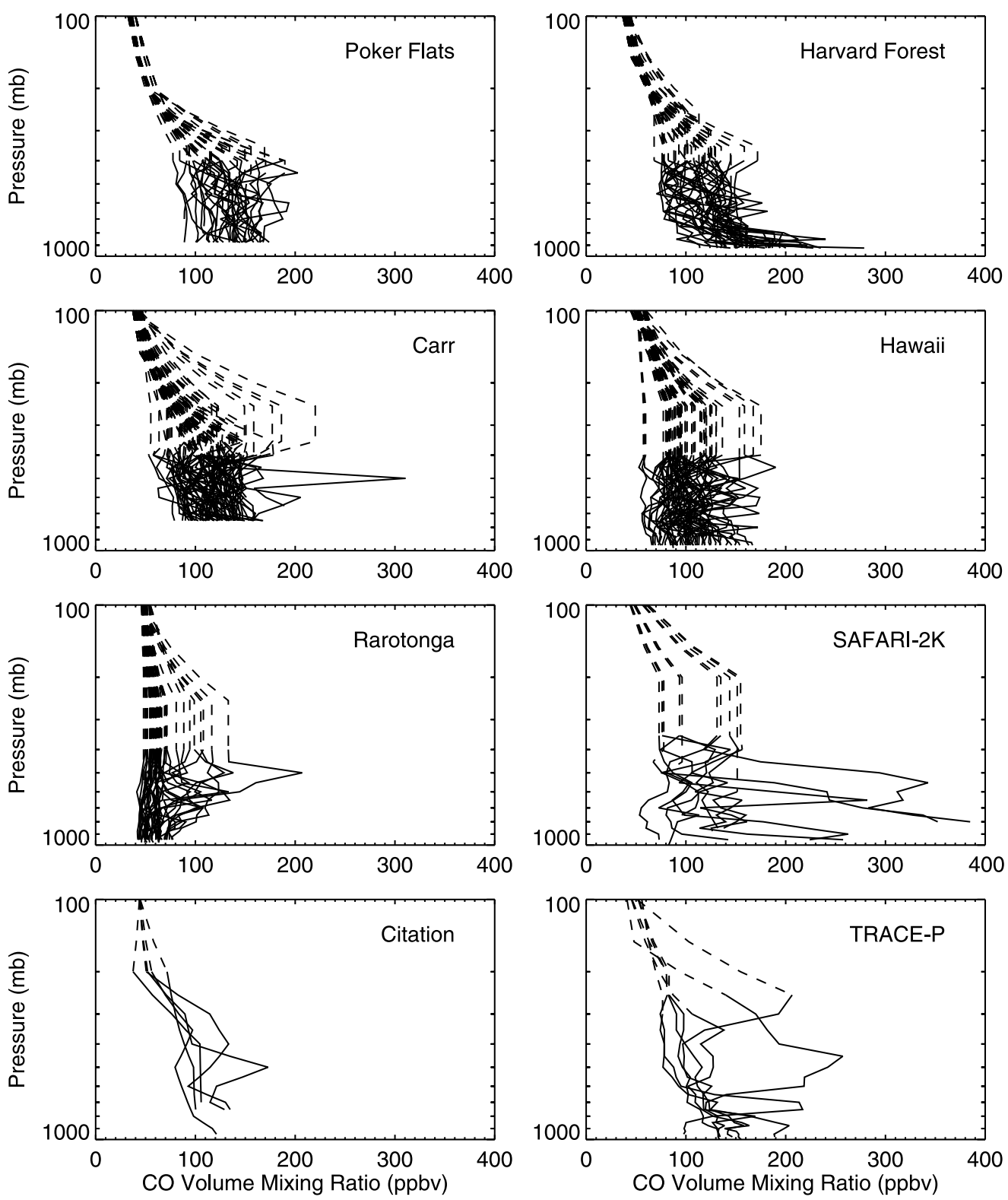

Figure 3. Regridded and vertically extended in situ CO profiles used for validation. Dashed line segments indicate parts of profile generated using chemical transport model climatology (see text).

CMDL data, a void exists between about 100 and 350 mbar where in situ data are desirable but are not typically available.

[16] A technique involving climatological output from the NCAR global chemical transport model MOZART-2 [Hauglustaine et al., 1998] was developed to extend the in situ profiles upward. Monthly means from a simulation driven with NCEP meteorology for 2001 are used. Both the in situ data and model output are interpolated to the standard 35-level vertical grid used in MOPFAS [Edwards et al., 1999]. The altitude of the tropopause is determined from the MOZART temperature profile. If the aircraft data do not reach the tropopause, the profile is extended by using the value at the highest altitude up to 2 levels below the tropopause. The profile is completed by a linear interpolation between that point and the model value immediately above the tropopause. The dashed line segments in Figure 3 represent the result of extending the in situ profiles vertically by the technique just described.

\section{Validation Radiance Processing}

[17] The MOPITT thermal channel validation radiances are calculated using the following sources as inputs to the forward radiative transfer model. Temperature and water vapor profiles are taken from National Center for Environmental Prediction (NCEP) reanalysis, and are temporally and spatially interpolated to the individual MOPITT pixels. Surface temperature, to which most of the MOPITT thermal channel radiances are very sensitive, and which exhibits large variability in space and time, is retrieved at each pixel from the $7 \mathrm{~A}$ radiance as described in the next paragraph. 

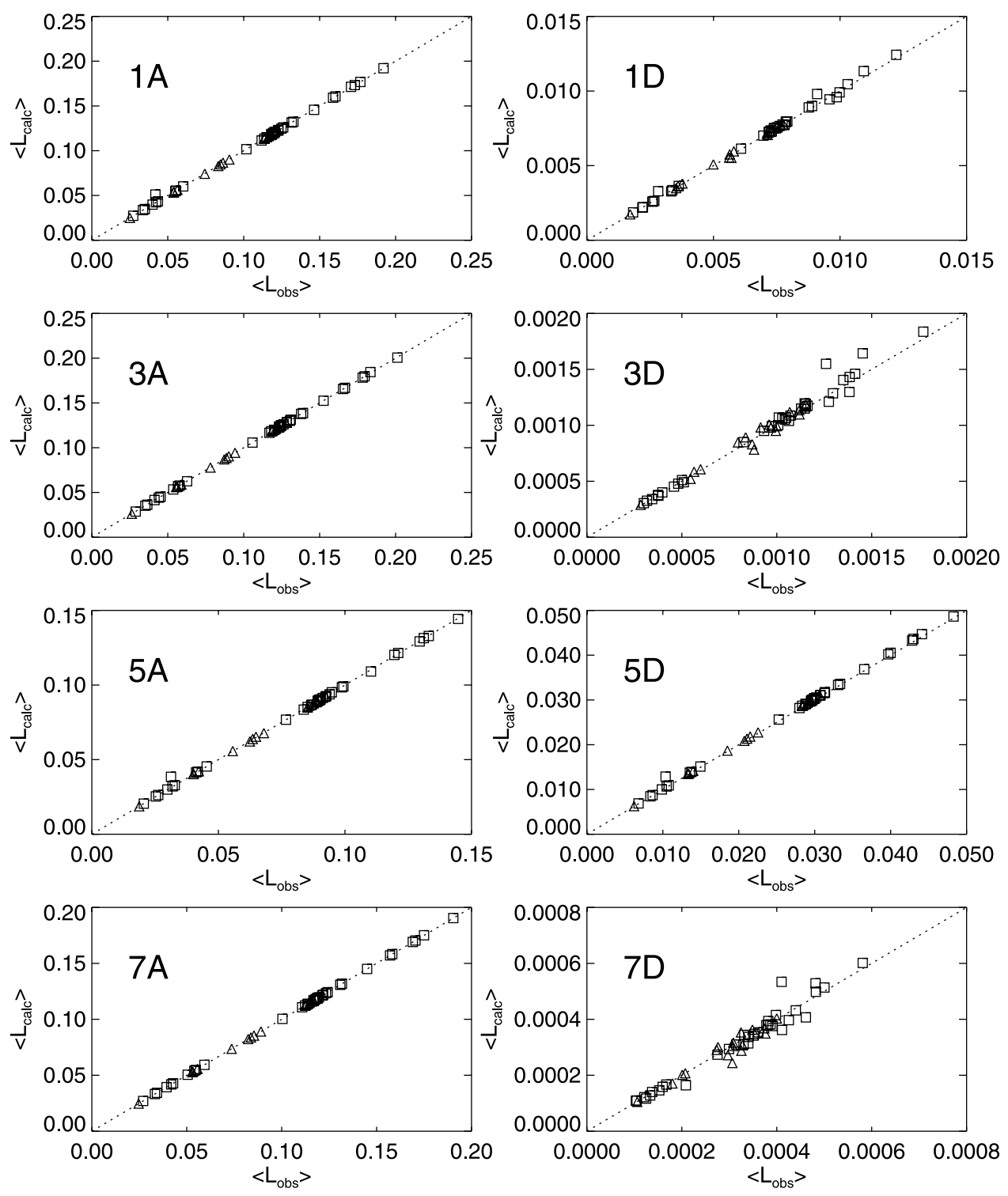

Figure 4. Scatterplots comparing scene-averaged satellite radiances and corresponding validation (model-calculated) radiances for the Phase I period and for all validation sites. Daytime and nighttime data are plotted with squares and triangles, respectively.

Surface emissivity also affects the thermal channel radiances. We assume fixed site-specific surface emissivity values, but also consider the effect of variable surface emissivity as a potential source of validation radiance error (see below). Surface emissivity values of 0.98 for the oceanic validation sites and 0.90 for the continental sites are assumed [Salisbury and D'Aria, 1994]. CO profiles needed as input to the forward model are generated from the in situ aircraft data as described above.

[18] Both surface temperature and emissivity influence the thermal channel radiances and are therefore included in the list of inputs to MOPFAS [Edwards et al., 1999]. For operational $\mathrm{CO}$ retrievals, the highly variable nature of surface temperature and emissivity (especially over land) inhibits their specification (i.e., as fixed values) to the required accuracy. Thus, in the MOPITT operational CO retrieval algorithm, surface temperature and emissivity are retrieved simultaneously with the CO profile [Deeter et al.,
2003]. We employ a similar technique for radiance evaluation. However, for radiance evaluation, surface temperature is retrieved as a single "stand-alone" product solely from the $7 \mathrm{~A}$ radiance. This technique is based on the assumption that the 7A radiance is itself unbiased. This particular radiance was selected because it exhibits the weakest sensitivity to $\mathrm{CO}$ (and therefore the highest mean atmospheric transmittance) of all the available thermal channel radiances [Pan et al., 1995]. In scenes with wellcharacterized surface temperature and emissivity, biases in each of the $\mathrm{CO}$ thermal channel A radiances (including 7A) were previously shown to be less than about $1 \%$ [Deeter et al., 2002].

[19] The retrieval of surface temperature (for validation radiance calculations) is accomplished using an adapted version of the operational $\mathrm{CO}$ retrieval algorithm in which the instrument noise values for all radiances other than the 7A radiance are artificially amplified. This noise-amplifica- 

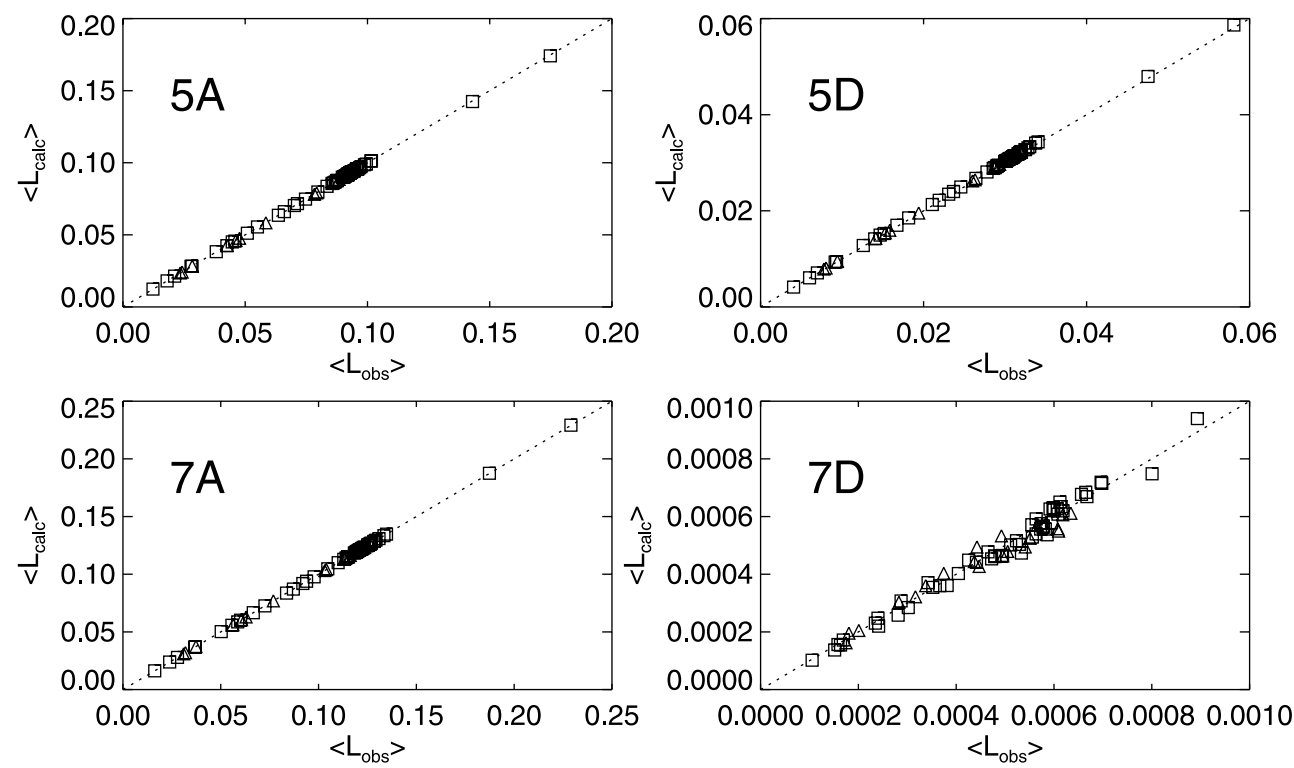

Figure 5. Scatterplots comparing scene-averaged satellite radiances and corresponding validation (model-calculated) radiances for the Phase II period and for all validation sites. Daytime and nighttime data are plotted with squares and triangles, respectively.

tion technique effectively disables all radiances other than 7A [Deeter et al., 2003]. Simultaneously, the a priori variance value for surface temperature is increased to $100 \mathrm{~K}^{2}$ and the a priori variance for surface emissivity is decreased to $1.0 \times 10^{-6}$. This combination of a priori variance values allows the surface temperature to vary during the retrieval iterations while keeping the surface emissivity confined to its a priori value. Thus the retrieved surface temperature is simply the value which, when fed to MOPFAS along with the site-specific surface emissivity and other ancillary data (temperature and water vapor profiles, etc.), reproduces the observed $7 \mathrm{~A}$ radiance.

[20] Validation radiances are calculated in the following manner. Each MOPITT overpass or "swath" coordinated with a CMDL sampling flight at a given validation site is processed individually. First, distances and temporal lags between all clear-sky MOPITT observations in the given MOPITT swath are calculated relative to the time and location of the CMDL sampling flight. Only clear-sky MOPITT pixels located within $200 \mathrm{~km}$ of the sampling flight and observed within 14 hours (either before or after the sampling flight) are retained. (In fact, most daytime MOPITT overpasses coincided with the sampling flights within just a few hours. A temporal window of 14 hours was selected as a means of additionally acquiring data from several fortuitous nighttime overpasses.) Only scenes including a minimum of ten MOPITT pixels satisfying these criteria are considered for further analysis. For each MOPITT pixel within this set, validation radiances are generated by (1) obtaining spatially and temporally interpolated NCEP temperature and water vapor profiles; (2) obtaining the pixel-dependent solar and satellite zenith angles; (3) retrieving the surface temperature from the observed 7A radiance as described in the previous paragraph; and finally (4) executing MOPFAS with these various inputs and the collocated regridded CMDL CO profile. Thus each MOPITT overpass coordinated with a sampling flight at a given validation site yields a set of $\mathrm{N}$ actual MOPITT observations $L_{o b s}^{i}(\mathrm{i}=1, \ldots \mathrm{N})$ and a corresponding parallel set of model-calculated radiances $L_{\text {calc }}^{i}$ (i.e., the "validation radiances"). For subsequent analysis, means are calculated for both data sets. Specifically, for each MOPITT thermal channel radiance and each MOPITT overpass of a validation sampling flight (i.e., a single "validation scene"), we calculate

$$
\begin{gathered}
\left\langle L_{o b s}\right\rangle=\frac{1}{N} \sum_{i=1}^{N} L_{o b s}^{i} \\
\left\langle L_{\text {calc }}\right\rangle=\frac{1}{N} \sum_{i=1}^{N} L_{\text {calc }}^{i} .
\end{gathered}
$$

\section{Validation Radiance Results}

[21] As described above each aircraft in situ profile coordinated with a single MOPITT overpass yields a mean calibrated satellite radiance $\left\langle L_{o b s}\right\rangle$ and a corresponding mean model-calculated radiance $\left\langle L_{\text {calc }}\right\rangle$ for each thermal channel radiance. The results for MOPITT observations and in situ profiles acquired during Phase I are presented as scatterplots in Figure 4. Each plotted symbol represents the results of averaging the satellite radiances and modelcalculated radiances for one MOPITT overpass of a validation site. Results for daytime and nighttime MOPITT overpasses are plotted as squares and triangles, respectively. (Several nighttime MOPITT overpasses for Carr, Colorado, Hawaii, and SAFARI-2000 coincided with aircraft sampling flights within the maximum temporal lag of 14 hours.) The dashed line in each panel represents perfect agreement between observed radiances and model-calculated radiances. Validation results for channels 5 and 7 during Phase II are presented in Figure 5.

[22] Because the 7A radiance is used during validation radiance processing to retrieve the surface temperature, it is 

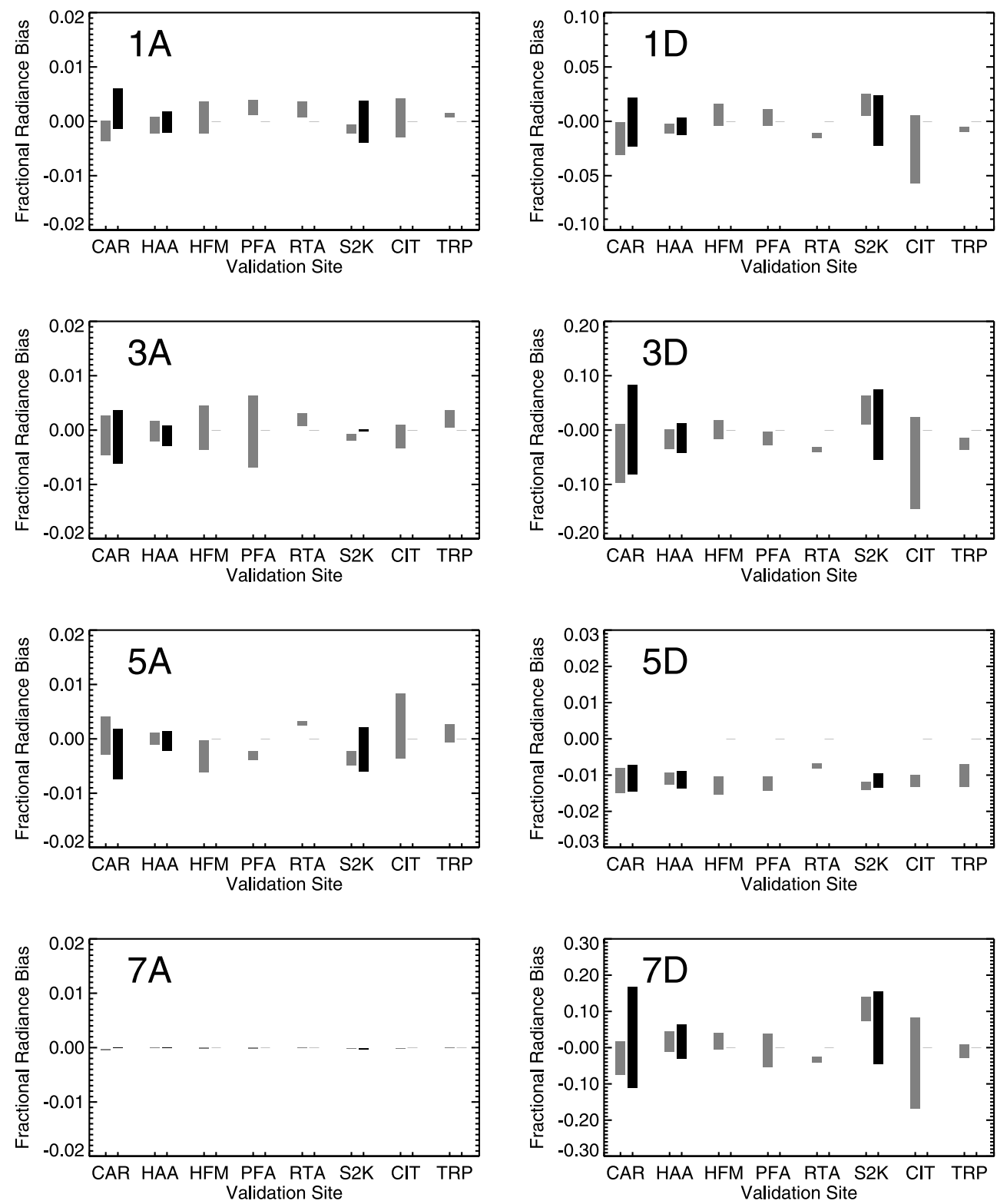

Figure 6. Fractional radiance biases calculated for each validation site for the Phase I period. Vertical limits of each bar represent the mean bias (for all MOPITT overpasses at that validation site) plus and minus 1 standard deviation. For sites where both daytime and nighttime statistics are represented, the vertical bar to the left corresponds to daytime overpass statistics, and the bar to the right corresponds to nighttime overpass statistics. See color version of this figure in the HTML.

expected and observed that $\left\langle L_{o b s}\right\rangle$ should almost exactly equal $\left\langle L_{\text {calc }}\right\rangle$ for the 7A radiance in Figures 4 and 5. More importantly, the agreement is also generally quite good for the other three $\mathrm{A}$ radiances over wide ranges of radiance values. As described earlier, the A radiances are typically characterized by much higher mean transmittance and lower trace-gas sensitivity than the D radiances. Variability of the A radiances is primarily due to surface temperature variability. Among the $\mathrm{D}$ radiances, agreement is poorest for the radiances associated with the two PMCs (i.e., 3D and 7D). This is also expected, since the weighting functions for the 3D and 7D radiances peak at higher levels than do the 1D and $5 \mathrm{D}$ radiances and therefore should be subject to larger relative errors due to the use of model $\mathrm{CO}$ climatology (rather than in situ data) in the upper troposphere and lower stratosphere.

[23] Radiance evaluation results are also quantified in terms of fractional radiance bias. For each set of satellite radiances and model-calculated radiances derived from a single MOPITT overpass of a validation site, the fractional radiance bias $(F R B)$ is defined as

$$
F R B \equiv \frac{\left\langle L_{o b s}\right\rangle-\left\langle L_{c a l c}\right\rangle}{\left\langle L_{\text {calc }}\right\rangle} .
$$

[24] Fractional radiance bias results for Phase I and Phase II are presented as bar plots in Figures 6 and 7. The vertical limits of each bar represent the mean FRB (with respect to all overpasses at a given validation site) plus and 

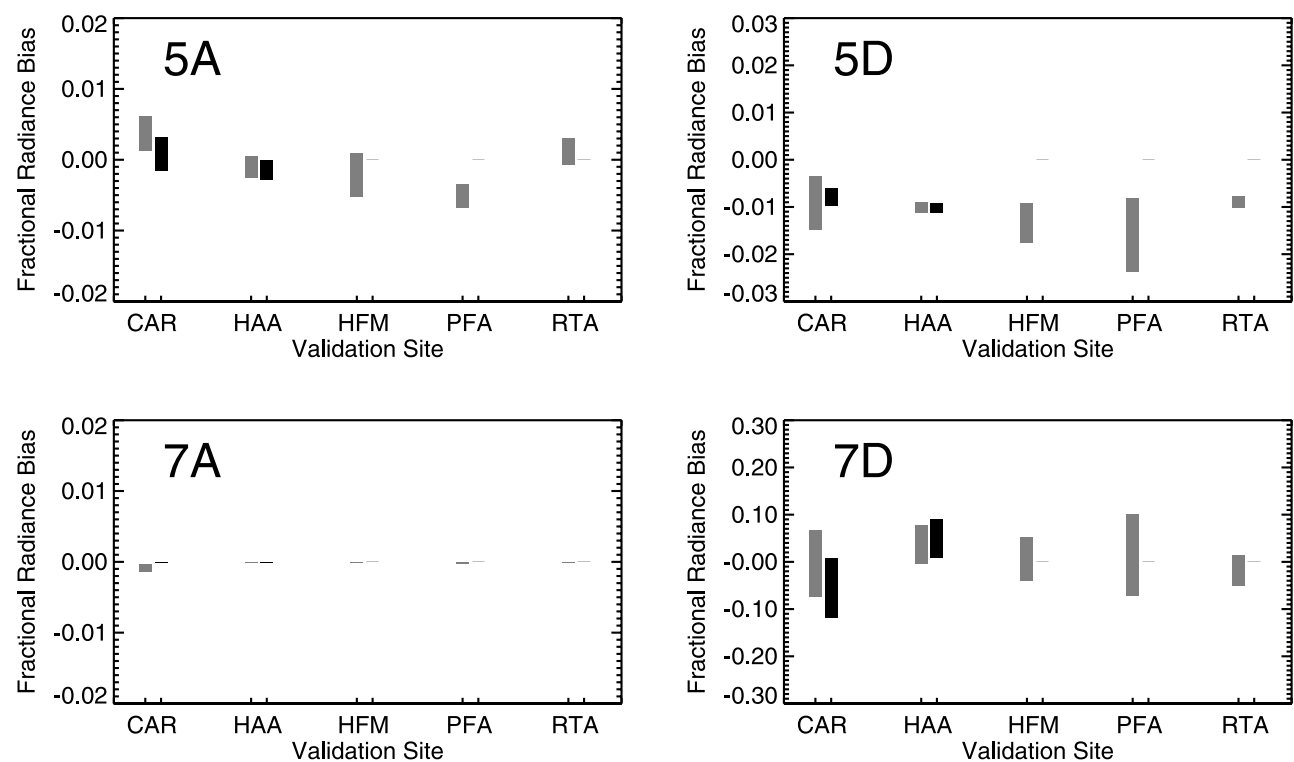

Figure 7. Fractional radiance biases calculated for each validation site for the Phase II period. Vertical limits of each bar represent the mean bias (for all MOPITT overpasses at that validation site) plus and minus 1 standard deviation. See color version of this figure in the HTML.

minus one standard deviation. The mean FRB values are also listed in Tables 4 and 5.

[25] For both Phase I and Phase II, the mean FRB for all of the MOPITT A radiances at all of the validation sites is generally within a few tenths of a percent of zero. However, the spread in the FRB values (i.e., the standard deviations) exhibits substantial variability. Generally, the spread in FRB values for the A radiances is smallest for the oceanic sites and largest for the continental sites. This may reflect the greater geophysical homogeneity (for example, with respect to surface temperature and emissivity) of the oceanic sites relative to the continental sites.

[26] Both the FRB means and the standard deviations for the MOPITT D radiances exhibit much greater variability than for the MOPITT A radiances. Compared to the A radiances, the $\mathrm{D}$ radiances are characterized by much greater trace gas sensitivity. Thus errors in the assumed $\mathrm{CO}$ profile will have a greater impact on the $\mathrm{D}$ radiances than on the $\mathrm{A}$ radiances. Such errors could arise, for example, either through spatial or temporal variability of the trace gas profile in the vicinity of a validation site, or through the use of chemistry model output to supplement the in situ data in the upper troposphere and stratosphere. Errors in the assumed temperature profile will also have a greater relative effect on the D radiances than on the A radiances [Wang et al., 1999].

[27] Except for the 5D radiance, Figures 6 and 7 do not indicate any systematic radiance bias for any of the radiances. Thus, except for 5D, random radiance errors appear to dominate any possible systematic bias. The $5 \mathrm{D}$ radiance apparently exhibits a persistent FRB of $\sim-1 \%$ for both Phases I and II. The cause of this bias is under investigation but might be related to instrument specifications assumed in MOPFAS. The effect of the bias on the $\mathrm{CO}$ retrieval results is described in the conclusion.

\section{Validation Radiance Analysis}

[28] The methodology employed for calculating the validation radiances suffers from several limitations, each of which could potentially impose radiance biases. In this section, we consider several geophysical sources of biases in the validation radiances.

\subsection{Effects of CO Temporal and Spatial Variability}

[29] For validation radiance calculations, we assume that in situ profiles sampled from aircraft are valid over circular regions up to $400 \mathrm{~km}$ in diameter and for up to 14 hours from the time of the sampling. The validity of this assumption probably varies significantly between validation sites. For example, Rarotonga lies in a relatively unpolluted area of the South Pacific. In this region, both the Intertropical Convergence Zone and the South Pacific Convergence Zone tend to form barriers to advected polluted air [Gregory et al., 1999]. As observed in Figure 3, CO variability at this site is much smaller than at sites like Carr, Colorado and Harvard Forest, Massachusetts, which are much closer to strong anthropogenic CO sources. The expected result of this geographic dependence of $\mathrm{CO}$ variability should be to produce the largest radiance errors at sites where $\mathrm{CO}$ variability is the greatest and the smallest errors where the variability is weakest. However, assuming that (1) the measured in situ profiles are generally unbiased (i.e., do not exhibit any systematic biases) relative to the mean $\mathrm{CO}$ profile over the surrounding 400-km-diameter region, and that (2) the thermal channel radiances exhibit a linear dependence on $\mathrm{CO}$ mixing ratio (over the range of expected $\mathrm{CO}$ mixing ratio values), $\mathrm{CO}$ temporal and spatial variability should not impose any systematic bias on the radiances. This means that validation sites characterized by greater $\mathrm{CO}$ variability might be associated with larger FRB standard deviations, but not with different FRB mean values.

\subsection{Effects of In Situ Extrapolation Technique}

[30] Because of aircraft altitude limits, the in situ profiles provided by CMDL do not span the entire vertical range defined by the MOPITT weighting functions. As described above, we developed a technique for generating validation 
Table 4. Phase I Site-Averaged Fractional Mean Radiance Biases ${ }^{\mathrm{a}}$

\begin{tabular}{|c|c|c|c|c|c|c|c|c|c|}
\hline Validation Site & Time of Day & $1 \mathrm{~A}$ & $3 \mathrm{~A}$ & $5 \mathrm{~A}$ & 7A & $1 \mathrm{D}$ & $3 \mathrm{D}$ & $5 \mathrm{D}$ & $7 \mathrm{D}$ \\
\hline Poker Flats & day & $0.25(0.14)$ & $-0.02(0.66)$ & $-0.30(0.08)$ & $-0.01(0.01)$ & $0.35(0.75)$ & $-1.57(1.26)$ & $-1.23(0.20)$ & $-0.86(4.57)$ \\
\hline Harvard Forest & day & $0.08(0.29)$ & $0.04(0.41)$ & $-0.32(0.29)$ & $-0.01(0.01)$ & $0.59(1.02)$ & $0.03(1.71)$ & $-1.28(0.24)$ & $1.77(2.26)$ \\
\hline Carr & day & $-0.18(0.19)$ & $-0.10(0.36)$ & $0.06(0.04)$ & $-0.04(0.01)$ & $-1.62(1.51)$ & $-4.35(5.42)$ & $-1.14(3.41)$ & $-2.79(4.59)$ \\
\hline Carr & night & $0.23(0.37)$ & $-0.12(0.49)$ & $-0.27(0.46)$ & $0.00(0.00)$ & $-0.06(2.26)$ & $0.15(8.24)$ & $-1.08(0.37)$ & $2.93(14.0)$ \\
\hline Hawaii & day & $-0.07(0.15)$ & $-0.03(0.19)$ & $0.00(0.11)$ & $0.00(0.00)$ & $-0.64(0.45)$ & $-1.62(1.80)$ & $-1.09(0.16)$ & $1.63(2.86)$ \\
\hline Hawaii & night & $-0.02(0.20)$ & $-0.10(0.19)$ & $-0.03(0.18)$ & $0.00(0.00)$ & $-0.48(0.79)$ & $-1.49(2.69)$ & $-1.14(0.24)$ & $1.71(4.75)$ \\
\hline Rarotonga & day & $0.21(0.14)$ & $0.19(0.12)$ & $0.29(0.04)$ & $0.00(0.00)$ & $-1.28(0.23)$ & $-3.58(0.48)$ & $-0.74(0.06)$ & $-3.28(0.75)$ \\
\hline TRACE-P & day & $0.11(0.04)$ & $0.20(0.16)$ & $0.10(0.17)$ & $0.00(0.00)$ & $-0.76(0.23)$ & $-2.51(1.06)$ & $-1.00(0.31)$ & $-0.89(1.86)$ \\
\hline SAFARI-2000 & day & $-0.15(0.08)$ & $-0.13(0.06)$ & $-0.36(0.13)$ & $-0.01(0.00)$ & $1.51(1.00)$ & $3.73(2.63)$ & $-1.30(0.11)$ & $10.61(3.36)$ \\
\hline SAFARI-2000 & night & $-0.01(0.39)$ & $0.00(0.02)$ & $-0.19(0.41)$ & $-0.01(0.01)$ & $0.06(2.31)$ & $1.07(6.43)$ & $-1.14(0.19)$ & $5.54(10.0)$ \\
\hline
\end{tabular}

${ }^{\mathrm{a}} \mathrm{Bias}$ values are expressed in percent. Values in parentheses are corresponding radiance bias standard deviations and are also in percent.

profiles using in situ data extended by output from chemistry model climatology to represent the upper troposphere and higher levels. The chemistry model climatology used to supplement the in situ data is based on MOZART monthly means spatially interpolated to the locations of the individual validation sites. Biases in the MOZART CO product would lead directly to biases in the model-calculated radiances. To quantify the sensitivities of the validation radiances to this effect, all validation radiances were recalculated after applying a positive bias of $10 \mathrm{ppbv}$ to the validation profile between (and inclusive of) the levels of $100 \mathrm{mbar}$ and $300 \mathrm{mbar}$. Recalculated validation radiance biases for the A radiances were typically within $0.1 \%$ of the nominal values listed in Table 4. This reflects the fact that the A radiances are relatively insensitive to the $\mathrm{CO}$ profile. Recalculated Phase I validation radiance biases for the $\mathrm{D}$ radiances are listed in Table 6. Compared to corresponding values in Table 4 , the effect of the applied $\mathrm{CO}$ mixing ratio bias is weakest for the $5 \mathrm{D}$ radiance (FRB differences of approximately $0.05 \%$ ) and greatest for the 7D radiance (FRB differences of $2-3 \%$ ).

[31] A further check on the effects of using modelcalculated mixing ratio values in the upper troposphere was made just using the TRACE-P profiles. These in situ profiles reached significantly higher maximum altitudes (between 200 and 250 mbar) than did the CMDL profiles. For this test, the in situ mixing ratio values for all levels where $\mathrm{p}<400$ mbar were replaced with modelcalculated values as if the actual maximum altitude of the in situ profile was 400 mbar. The recalculated FRB values for the thermal channel A radiances for this experiment were all within $0.1 \%$ of the nominal values (calculated using the entire in situ profile) listed in Table 4. For the thermal channel D radiances, the recalculated
FRB value decreased by $0.03 \%$ for $5 \mathrm{D}$, increased by $0.28 \%$ for $1 \mathrm{D}$, increased by $1.01 \%$ for $3 \mathrm{D}$ and increased by $1.91 \%$ for 7D. These results are generally in good agreement with the simulated effects of a $10 \mathrm{ppbv}$ mixing ratio bias described in the previous paragraph.

\subsection{Effects of Assumed Surface Emissivity}

[32] In the spectral region around 4.7 microns, reflectivities of common terrestrial surface materials vary from a few percent up to approximately 30 percent [Salisbury and D'Aria, 1994]. Corresponding surface emissivity values range between about 0.7 and 1.0. However, both water and green foliage, which together cover the vast majority of the Earth's surface, exhibit reflectance values of only a few percent (emissivity values near one). Low emissivity values occur in this band for less common surface materials including "senescent foliage" [Salisbury and D'Aria, 1994] and some inorganic materials such as silt and sand [Snyder et al., 1997]. As described earlier, fixed surface emissivity values of 0.98 (for the oceanic validation sites) and 0.90 (for the land-based sites) are assumed for validation radiance calculations. For the oceanic sites, the uncertainty in the assumed surface emissivity value is negligible. On the other hand, the assumed emissivity value of 0.90 for the land-based sites could be in error by as much as approximately 0.2 in rare circumstances. To quantify this source of error, the validation radiances for the continental validation sites were recalculated assuming a surface emissivity value of 0.70. Recalculated validation radiances for the A radiances were typically within $0.1 \%$ of the nominal values listed in Table 4. Recalculated Phase I validation radiances for the D radiances are listed in Table 7. Compared to corresponding values in Table 4 , the effect of the smaller assumed surface emissivity value is weakest for the $5 \mathrm{D}$

Table 5. Phase II Site-Averaged Fractional Mean Radiance Biases ${ }^{\mathrm{a}}$

\begin{tabular}{|c|c|c|c|c|c|}
\hline Validation Site & Time of Day & $5 \mathrm{~A}$ & $7 \mathrm{~A}$ & $5 \mathrm{D}$ & $7 \mathrm{D}$ \\
\hline Poker Flats & day & $0.52(0.16)$ & $-0.01(0.01)$ & $-1.59(0.78)$ & $1.53(8.61)$ \\
\hline Harvard Forest & day & $-0.21(0.31)$ & $0.00(0.00)$ & $-1.34(0.42)$ & $0.56(4.58)$ \\
\hline Carr & day & $0.37(0.24)$ & $-0.09(0.06)$ & $-0.92(0.56)$ & $-0.40(7.02)$ \\
\hline Carr & night & $0.08(0.23)$ & $-0.02(0.00)$ & $-0.79(0.18)$ & $-5.51(6.27)$ \\
\hline Hawaii & day & $-0.10(0.15)$ & $0.00(0.00)$ & $-1.02(0.11)$ & $3.72(4.06)$ \\
\hline Hawaii & night & $-0.15(0.14)$ & $0.00(0.00)$ & $-1.02(0.10)$ & $4.98(4.03)$ \\
\hline Rarotonga & day & $0.12(0.19)$ & $0.00(0.00)$ & $-0.89(0.13)$ & $-1.82(3.20)$ \\
\hline
\end{tabular}

${ }^{a}$ Bias values are expressed in percent. Values in parentheses are corresponding radiance bias standard deviations and are also in percent. 
Table 6. Phase I Site-Averaged Fractional Mean Radiance Biases (D-Radiances Only) Calculated With Bias Applied to Upper Tropospheric $\mathrm{CO}^{\mathrm{a}}$

\begin{tabular}{lccccc}
\hline Validation Site & Time of Day & 1D & 3D & 5D & 7D \\
\hline Poker Flats & day & 0.67 & -0.52 & -1.25 & 0.83 \\
Harvard Forest & day & 0.93 & 1.18 & -1.31 & 3.74 \\
Carr & day & -1.26 & -3.17 & -1.18 & -0.71 \\
Carr & night & 0.34 & 1.66 & -1.13 & 5.72 \\
Hawaii & day & -0.26 & -0.26 & -1.12 & 4.13 \\
Hawaii & night & -0.11 & -0.18 & -1.17 & 4.10 \\
Rarotonga & day & -0.88 & -1.99 & -0.79 & -0.15 \\
Citation & day & -2.19 & -4.79 & -1.20 & -1.91 \\
TRACE-P & day & -0.39 & -1.16 & -1.04 & 1.64 \\
SAFARI-2000 & day & 1.85 & 4.94 & -1.32 & 12.80 \\
SAFARI-2000 & night & -0.46 & 2.49 & -1.18 & 8.11 \\
\hline
\end{tabular}

${ }^{\mathrm{a}}$ Values expressed in percent.

radiance (typical FRB differences of approximately $0.1 \%$ ) and greatest for the $1 \mathrm{D}, 3 \mathrm{D}$, and $7 \mathrm{D}$ radiances (FRB differences of up to $2 \%$ ).

\subsection{Other Effects}

[33] The potential sources of radiance bias just described only include those directly associated with the validation methodology. A comprehensive analysis of all of the sources of validation radiance errors would need to consider several additional effects. The MOPITT cloud detection algorithm probably does not detect all MOPITT observations which are partially cloud-filled. The effect of this residual cloud contamination would likely depend on the type of cloud and would vary significantly by signal. For example, the PMC D radiances would not likely be severely affected by low-level clouds, since their weighting functions are relatively weak near the surface. Like clouds, the effects of aerosols are also not treated in the operational forward model. Errors in the interpolated NCEP meteorological data should also be considered. Over land, for example, the diurnal variability of the temperature profile within the boundary layer may not be well represented by interpolated NCEP reanalysis. Sun glint, which occurs when solar radiation at $4.7 \mu \mathrm{m}$ is specularly reflected from bodies of open water into the MOPITT field of view, represents yet another potential source of error. Forward model errors are possible both from errors in the HITRAN spectral database and from the parameterizations necessary to produce computationally efficient computer code. Finally, instrumental sources of radiance biases should also be analyzed in detail.

\section{Conclusion}

[34] Optimum performance of the MOPITT CO retrieval algorithm requires that the operational forward radiative transfer model be unbiased relative to the actual calibrated satellite radiances. Radiance biases of just one percent can produce large retrieval biases. We have therefore developed and applied a methodology for systematically comparing the calibrated MOPITT radiances with calculated values using the operational forward model over widely varying atmospheric and geographic settings. in situ data sampled from aircraft in coordination with overpasses of the Terra satellite serve as the foundation for MOPITT validation efforts. With few exceptions, calibrated radiances for the thermal channel A radiances agree with model-calculated values to within a few tenths of a percent, whereas calibrated radiances for the thermal channel $\mathrm{D}$ radiances agree with model-calculated values to within a few percent. Thus, over widely ranging atmospheric conditions, the MOPITT operational forward model quite accurately predicts observed MOPITT radiances. Much greater consistency in the biases is observed for the oceanic validation sites (i.e., Hawaii, Rarotonga, and the TRACE-P region) than for the continental sites. This observation is consistent with the expectation that $\mathrm{CO}$ temporal and spatial variability should be greatest in the vicinity of localized sources of CO. For example, measurements over Carr, Colorado are affected by anthropogenic emissions throughout much of the western United States whereas southern Africa is the site of widespread seasonal biomass burning. Surface emissivity uncertainty might also lead to greater validation radiance errors for the continental sites. We therefore place greater confidence on the derived radiance bias values for the oceanic sites than on the values for the continental sites.

[35] Currently, in "Version 3" of the MOPITT operational retrieval products, only the $7 \mathrm{~A}, 1 \mathrm{D}, 3 \mathrm{D}$, and $7 \mathrm{D}$ radiances are used for Phase I retrievals, while the $5 \mathrm{~A}, 5 \mathrm{D}$, and $7 \mathrm{D}$ radiances are used for Phase II retrievals. Since the Phase I results do not indicate any obvious overall biases in either the channel 1,3 , or $7 \mathrm{D}$ radiances, no empirical biascompensating correction factors are used in Version 3 Phase I CO retrievals. However, the persistent observed bias of approximately $-1 \%$ in the $5 \mathrm{D}$ radiance (for both Phase I and Phase II radiances) would, without correction, significantly degrade Phase II retrievals. Since even a $0.1 \%$ bias in $5 \mathrm{D}$ leads to retrieval biases on the order of tens of ppbv (as indicated by Phase II retrieval simulation results), a bias of $-1 \%$ would clearly produce unacceptable results (either because it would cause large retrieval biases or because it would inhibit the convergence of the retrieval algorithm). Therefore an empirical correction factor is used in Version 3 Phase II retrievals to compensate for the observed 5D bias. The method for determining this bias compensation factor and its effect on the $\mathrm{CO}$ retrieval results will be described in

Table 7. Phase I Site-Averaged Fractional Mean Radiance Biases (D-Radiances Only) for Land-Based Validation Sites Calculated With Reduced Value of Surface Emissivity ${ }^{\mathrm{a}}$

\begin{tabular}{lccrrr}
\hline Validation Site & Time of Day & 1D & 3D & 5D & 7D \\
\hline Poker Flats & day & 2.23 & 0.28 & -0.99 & 0.66 \\
Harvard Forest & day & 2.22 & -0.91 & -3.26 & -1.13 \\
Carr & day & -1.15 & -1.76 & -1.15 & -1.32 \\
Carr & night & -2.16 & -5.24 & -1.09 & 0.60 \\
Citation & day & 1.60 & 3.92 & -1.22 & -3.41 \\
SAFARI-2000 & day & -1.22 & -0.39 & -1.28 & 10.85 \\
SAFARI-2000 & night & & & 4.17 \\
\hline
\end{tabular}

${ }^{a}$ Values expressed in percent. 
a future publication. Possible causes for the 5D bias and methods for removing it are under investigation.

[36] Acknowledgments. The University of Toronto MOPITT team would like to acknowledge the Canadian Space Agency (CSA) for the instrument financing, the Natural Sciences and Engineering Research Council (NSERC) and Meteorological Service of Canada (MSC) for help with the data processing, COMDEV (the prime contractor), ABB BOMEM, and the University of Toronto. The NCAR MOPITT project is supported by the National Aeronautics and Space Administration (NASA) Earth Observing System (EOS) Program. The National Center for Atmospheric Research (NCAR) is sponsored by the National Science Foundation.

\section{References}

Deeter, M. N., G. Francis, D. P. Edwards, J. C. Gille, E. McKernan, and J. R. Drummond (2002), Operational validation of the MOPITT instrument optical filters, J. Atmos. Oceanic Technol., 19, 1772-1782.

Deeter, M. N., et al. (2003), Operational carbon monoxide retrieval algorithm and selected results for the MOPITT instrument, J. Geophys. Res., 108(D14), 4399, doi:10.1029/2002JD003186.

Edwards, D. P., C. M. Halvorson, and J. C. Gille (1999), Radiative transfer modeling for the EOS Terra satellite Measurements of Pollution in the Troposphere (MOPITT) instrument, J. Geophys. Res., 104, 16,75516,775

Emmons, L. K., et al. (2004), Validation of Measurements of Pollution in the Troposphere (MOPITT) CO retrievals with aircraft in situ profiles, J. Geophys. Res., 109, doi:10.1029/2003JD004101, in press.

Gregory, G. L., et al. (1999), Chemical characteristics of Pacific tropospheric air in the region of the Intertropical Convergence Zone and South Pacific Convergence Zone, J. Geophys. Res., 104, 5677-5696.

Hauglustaine, D. A., G. P. Brasseur, S. Walters, P. J. Rasch, J.-F. Muller, L. K. Emmons, and M. A. Carroll (1998), MOZART, a global chemical transport model for ozone and related chemical tracers: 2 . Model results and evaluation, J. Geophys. Res., 103, 28,291-28,335.

Jacob, D. J., J. H. Crawford, M. M. Kleb, V. S. Connors, R. J. Bendura, J. L. Raper, G. W. Sachse, J. C. Gille, L. Emmons, and C. L. Heald (2003), Transport and Chemical Evolution over the Pacific (TRACE-P) aircraft mission: Design, execution, and first results, J. Geophys. Res., 108(D20), 8781, doi:10.1029/2002JD003276.

McMillin, L. M., L. J. Crone, M. D. Goldberg, and T. J. Kleespies (1995), Atmospheric transmittance of an absorbing gas, 4, OPTRAN: A computationally fast and accurate transmittance model for absorbing gases with fixed and with variable mixing ratios at variable viewing angles, $\mathrm{Appl}$. Opt., 34, 6269-6274.

Novelli, P. C., et al. (1998), An internally consistent set of globally distributed atmospheric carbon monoxide mixing ratios developed using results from an intercomparison of measurements, J. Geophys. Res., 103, 19,285-19,293

Pan, L., D. P. Edwards, J. C. Gille, M. W. Smith, and J. R. Drummond (1995), Satellite remote sensing of tropospheric $\mathrm{CO}$ and $\mathrm{CH}_{4}$ : Forward model studies of the MOPITT instrument, Appl. Opt., 34, 6976-6988.

Pan, L., J. Gille, D. P. Edwards, P. L. Bailey, and C. D. Rodgers (1998), Retrieval of tropospheric carbon monoxide for the MOPITT instrument, J. Geophys. Res., 103, 32,277-32,290.

Sachse, G. W., G. F. Hill, L. O. Wade, and M. G. Perry (1987), Fastresponse, high-precision carbon monoxide sensor using a tunable diode laser absorption technique, J. Geophys. Res., 92, 2071-2081.

Salisbury, J. W., and D. M. D'Aria (1994), Emissivity of terrestrial materials in the 3-5 $\mu \mathrm{m}$ atmospheric window, Remote Sens. Environ., 47, $345-$ 361.

Snyder, W. C., Z. Wan, Y. Zhang, and Y. Z. Feng (1997), Thermal infrared $(3-14 \mu \mathrm{m})$ bidirectional reflectance measurements of sands and soils, Remote Sens. Environ., 60, 101-109.

Taylor, F. W. (1983), Pressure modulator radiometry, in Spectroscopic Techniques, vol. 3, pp. 137-197, Academic, San Diego, Calif.

Tolton, B. T., and J. W. Drummond (1997), Characterization of the lengthmodulated radiometer, Appl. Opt., 36, 5409-5419.

Wang, J., J. C. Gille, P. L. Bailey, J. R. Drummond, and L. Pan (1999), Instrument sensitivity and error analysis for the remote sensing of tropospheric carbon monoxide by MOPITT, J. Atmos. Oceanic Technol., 16, 465-474.

Warner, J., J. Gille, D. P. Edwards, D. Ziskin, M. Smith, P. Bailey, and L. Rokke (2001), Cloud detection and clearing for the Earth Observing System Terra satellite Measurements of Pollution in the Troposphere (MOPITT) experiment, Appl. Opt., 40, 1269-1284.

J.-L. Attie, Laboratoire d'Aérologie, Observatoire Midi Pyrénées, 14 Avenue E. Belin, F-31400 Toulouse, France. (attj1@aero.obs-mip.fr)

J. Chen, M. N. Deeter, D. P. Edwards, L. K. Emmons, G. L. Francis, J. C. Gille, S.-P. Ho, B. Khattatov, J.-F. Lamarque, D. Mao, D. Packman, J. X. Warner, V. Yudin, and D. Ziskin, Atmospheric Chemistry Division, National Center for Atmospheric Research, P. O. Box 3000, Boulder, CO 80307 , USA. (jschen@ucar.edu; mnd@ucar.edu; edwards@ucar.edu; emmons@ ucar.edu; gfrancis@ucar.edu; gille@ucar.edu; spho@ucar.edu; boris@ucar. edu; lamar@ucar.edu; dmao@ucar.edu; pack@ucar.edu; juying@ucar.edu; vyudin@ucar.edu; ziskin@ucar.edu)

J. R. Drummond, Department of Physics, University of Toronto, 60 St. George Street, Toronto, Ontario, Canada M5S 1A7. (jim@atmosp.physics. utoronto.ca)

P. Novelli, Climate Monitoring and Diagnostics Laboratory, NOAA, R/E/ CG1,325 Broadway, Boulder, CO 80303, USA. (pnovelli@cmdl.noaa.gov) G. Sachse, NASA Langley Research Center, Mail Stop 472, Hampton, VA 23681-2199, USA. (g.w.sachse@larc.nasa.gov) 